\title{
Searching for Educational Ideas for Children in F. W. Parker's Life Path and Its Implications for Taiwan's Education
}

\author{
Yi-Huang Shih \\ Department of Early Childhood Educare, Ching Kuo Institute of Management and Health, Taiwan
}

Received April 15, 2020; Revised May 26, 2020; Accepted June 16, 2020

Copyright (C2020 by authors, all rights reserved. Authors agree that this article remains permanently open access under the terms of the Creative Commons Attribution License 4.0 International License

\begin{abstract}
F. W. Parker was born in New Hampshire, New England, USA, in 1937. Parker's experiences of nature during the time he spent on a farm as a young boy comprise an important period in his life. Moreover, his practical experience of enrollment into teaching positions after graduation, his travels and study in European countries, his tenure as the Superintendent of the Quincy area, and, finally, his appointment as the Principal of Chicago Cook County Normal School are all important life events that shaped Parker's philosophy of children education. By reading and analyzing related literature, this essay searches for educational ideas for children in Parker's light of life path and investigates its implications for Taiwan's education. Parker's educational ideas for children are as follows: (1) children need to be closer to nature, (2) play can ensure a happy life for children in the future, (3) nature music should be integrated into children's learning, (4) teachers should integrate stories into their teaching, (5) teachers need to motivate children's learning interests, (6) children's attention requires cultivation, (7) children should enjoy freedom of expression, and (8) children should be at the center of education processes. Finally, ideas inspired by Parker's life path are applied to contemporary education in Taiwan. The author discusses enlightenment from three aspects: experimental education, adaptive education, and the practice of educational love. This essay hopes to broaden the understanding of Parker's educational ideas for children and utilize this knowledge to expand the horizon of Taiwanese education.
\end{abstract}

Keywords Adaptive Education, Childhood Education, Experimental Education, F. W. Parker

\section{Introduction}

F. W. Parker was born in New Hampshire, New England,
USA, in 1937. His father died when he was 6 years old. His family's impoverished state drove Parker to become a farmer's apprentice when he was 8 years old. While on the farm, Parker educated himself and enjoyed reading books owned by the farmer. At the age of 13 years, he ceased to be an apprentice and began receiving education. He served as a rural teacher at the age of 16 years and gradually worked his way up to becoming the Principal of Ilinois Carrolton Elementary School in Illinois at the age of 20 years. During his tenure as president of the school, the American Civil War broke out. Parker volunteered to join the federal army and was wounded and captured. After the war ended, he once again began engaging in education until 1872, which was the year when Parker went to study in Europe and was personally exposed to educational theories formulated by educational thinkers such as J. H. Pestalozzi, J. F. Herbart, and F. W. A. Fröbel (Cremin, 1964).

In 1875, he returned to the United States and first served as an Inspector for the Quincy Schools, Massachusetts. Later, he transferred to the Cook County Normal School in 1883; thereafter, he was appointed as the Head of the Chicago Institute, which later became a part of the University of Chicago (Hsu, 1975). According to J. Dewey, the American progressive education movement started in 1875 when Parker established a school in Quincy, Massachusetts. Hence, Parker is revered as the father of progressive education. In his five years at Quincey, Parker revitalized the educational spirit of the school. Parker opposed the formalism of traditional education and proposed "quality teaching." He advocated that children should be the focal point of schools, and that their development during childhood should gain precedence over preparing them for the future (Dewey, 1930; Yang, 1982). However, to understand the life and philosophy of Parker, his views on children's education should not be separated from his life path (Merle, 1935; Parker, 1969). For this reason, this essay explores Parker's views on 
children education by studying his life trajectory through literature analysis and illuminates its implications for education in Taiwan.

\section{Children's Educational Ideas Influenced by Parker's Life Path}

Parker's life trajectory influenced his ideas pertaining to children's education. His experiences of nature while working on a farm, practical experience of enrollment into teaching positions after graduation, his travels and study in European countries, his tenure as the Superintendent of the Quincy area, and, finally, his appointment as the Principal of Chicago Cook County Normal School are notable life experiences.

\subsection{Parker's Experiences of Nature on Farm}

Parker was born on October 9, 1837, in a rural family in Bedford, New Hampshire-an area populated by Puritans. His father died when Parker was 6 years old, which brought hardships and poverty into Parker's life. To overcome these hardships, Parker began work at a farm as an apprentice when he was 8 years old (Patridge, 1896). Having worked on the farm for more than 5 years, Parker learned a lot about nature, flora and fauna, insects, and astronomy; in his spare time, Parker would read books owned by the farmer. Parker's experiences of nature while at the farm made him recognize the importance of play for children. During this time, he also discovered the importance of being close to nature and cultivated sharp observation for children in nature. His experience at the farm influenced how he designed the curriculum at Quincy. There was special emphasis on travel and field trips, and children were often encouraged to observe nature (Dangler, 1939; Hsu, 1975; Wu, 1995). For example, Parker travelled with children to acquire knowledge during geography classes. At the age of 13 years, Parker ceased to be a farm apprentice and began receiving education through part-time schooling (Patridge, 1896).

\subsection{Practical Experience from Teaching after Early Graduation}

Since childhood, Parker's dream and sole ambition was to become a teacher. Driven by his passion for education, Parker graduated from high school in 1854 and immediately became a teacher in a rural school (Patridge, 1896).

In the fall of 1858, 20-year-old Parker became the principal of a primary school in Carrollton, Illinois, where he served until the outbreak of the American Civil War in the spring in1861. Once the war began, Parker resigned from his teaching position and entered military service in 1862. On account of his good performance in the war,
Parker was awarded the rank of Colonel; hence, he was often known as Colonel Parker (Cremin, 1964; Patridge, 1896).

Although Parker was a soldier, he loved peace more than war (Patridge, 1896). After the war, Parker returned to school and resumed his engagement with education. In 1865, he first served as a teacher at the North Carolina grammar school in New Hampshire (the North Grammar School of Manchester). Three years later, he went to Ohio to manage the schools in the first district. During this teaching period, Parker gained some practical experience in teaching; however, Parker often prioritized reading and learning contemporary educational theory over teaching affairs. He also forwarded the idea of visiting educational thinkers in Europe, which influenced the ideas Parker later developed for children's education (Cremin, 1964; Patridge, 1896).

\subsection{Travels and Study in European Countries}

After inheriting a small legacy from his aunt (Cremin, 1964), Parker moved to Berlin, Germany, in the fall of 1872 for two and a half years of study of the subjects of philosophy, history, and education (Patridge, 1896). After two and a half years of study in Europe, Parker systematically studied the educational theories of continental education scholars such as Rousseau, Pestalozzi, Fröbel, and Herbart (Cremin, 1964). From Rousseau, Parker gained a romantic and naturalistic view of children; from Pestalozzi, Parker recognized the importance of love in the reformation process. Additionally, he developed a method of intuitive teaching wherein children observed nature directly. Parker believed that children should be encouraged to learn in nature to unleash their potential. He also emphasized the importance of handwork in education. From Fröbel, Parker learned that education entails a harmonious growth of body, mind, and spirit. He also derived his theory of concentration from Herbart's concentration and correlation principles (Chu, 2010).

Parker's travels and study in Europe greatly shaped his views on childhood education. Parker's ideas were deeply rooted in European educational scholars' conceptualization of children's education. He hoped to bring his ideas on children's education back to the United States to completely reform American education (Dangler, 1939; Patridge, 1896; Wu, 1995).

\subsection{Appointment as the Superintendent of the Quincy Area}

After returning to the United States in 1875, Parker was appointed as the Superintendent of the Quincy area of Massachusetts; he was responsible for education supervision and educational guidance in the area. Before Parker arrived at Quincy, Quincy students were proficient 
in grammar and spelling but could not write a single letter. The board wished to improve the quality of education of all schools in the area and was, hence, anxious to appoint a person who could help with this. Because Parker had learned novel educational concepts from the European continent and had practical education experience to his credit; hence, he was chosen to manage schools in Quincy (Cremin, 1964).

After reaching Quincy, Parker abandoned the stereotypical teaching methods of the past. Language learning courses were no longer subdivided into listening, speaking, reading, and writing. Parker allowed children to learn simple words or sentences concerning daily life instead of making them memorize letters and grammar rules, which was the norm. Simultaneously, he asked teachers to select interesting and child-appropriate magazines, newspapers, and stories. Parker's curriculum integrated children's life experiences, and he recognized the importance of cultivating the interest of children for efficient learning. Further, children were encouraged to express themselves while learning. In case of arithmetic learning, Parker changed the traditional method of reciting formulas and arithmetic rules, which was in vogue, and included physical objects to guide children's counting and calculation (Chang, 1998; Cremin, 1964).

\subsection{Appointment as the Principal of Chicago Cook County Normal School}

Parker left Quincy in 1880 to work as a superintendent in the Boston School District (Cremin, 1964). In 1883, Parker resigned as the superintendent to advance his explorations into the inner world of children (Parker, 1969). From 1883 to 1898, Parker served as the Principal of Cook County Normal School in Chicago. Many school teachers benefited from the innovations in Parker's teaching methods (Harris, 1898). As a principal, Parker established his school as a center for teacher training centers and experimental education (Cremin, 1964; Wu, 1995).

Parker highlighted that it is the teachers' responsibility to shape the features of life, society, and nation, and the function of regular schools is to educate pupils to undertake their responsibilities; hence, normal schools are more important than other higher educational institutions. Normal schools should broaden their horizon to educate teachers and function as a laboratory for educational experiments. Normal schools must penetrate, influence, and improve education and educational thinking. Therefore, Parker wanted the Cook County Normal School in Chicago to offer the best teachers, the best education, the best culture, the best professional training, and the best experience (Parker, 1902). Parker valued the importance of teachers and understood that the future of education is based on teachers' professional education (Harper, Lane, Dewey, \& Hirsch, 1902). Therefore, the success of children's education is based on teachers' competence.

\section{Discussing Children's Educational Ideas in Parker's Life Path}

After reading and analyzing related literature (Chang, 1998; Cremin, 1964; Huang, 2005; Parker, 1896, 1897, 1900a, 1901a, 1901b, 1901c, 1902, 1969; Parker, \& Helm, 1898; Parker, Cooke, \& Stilwell, 1901; Parker \& Helm, 1902) and exploring children's educational ideas in F. W. Parker's life path, the following children's educational ideas are presented.

\subsection{Children Need to be Closer to Nature}

Memories of the farm are always imprinted in the sensitive minds of all children who have lived in countryside farm. Having spent more than five years at the farm, Parker recognized the value of children's proximity to nature. Abounding with teaching materials, nature provides a resourceful platform for educating children. Children can freely cultivate the holistic development of their body, mind, and spirit in nature (Parker \& Helm, 1902; Parker, 1969). Further, Parker pointed out that the unremitting energy of nature can be utilized to quickly transform children's instincts into spontaneous actions. Additionally, nature can ignite children's energy levels, release the powers of imagination, and shape and guide their activities (Parker, 1902).

\subsection{Play can Ensure a Happy Future for Children}

Having spent more than 5 years on the farm, Parker learned the importance of play for children. Play can ensure a happy future for children (Parker \& Helm, 1898). Play entails active preparation for work (Parker \& Helm, 1902). Play has educational value (Parker, 1900), especially the sport of kite flying, which has its mysterious side (Parker \& Helm, 1902). Therefore, teachers should integrate play into the curriculum design.

\subsection{Integrating Nature Music into Children's Learning}

Nature music should be integrated into children's learning. Experiences at the farm made Parker understand that one of the first sounds children make is an imitation of rhythm. Children are highly sensitive to the rhythm of music. Music impacts children in wonderful ways, even before a child acquires consciousness and still has an obscure sense of self. Lullabies soothe children to sleep, transforming their pain into pleasure. Human beings are highly sensitive to the rhythm of music. Not only can music soothe and lull children to sleep, but the first dawning of consciousness, marked by a smile, can be triggered by a song. The first spiritual breath of external life can be experienced through musical cadence. The whole universe moves in rhythm: avalanches thunder down mountain sides in deep cadences; ocean waves roar in musical cadence. 
The rippling of a brook and the sound of breeze moving through foliage represent simple nature music. Little children are at the center of the rhythms of the earth, through which the universe whispers its sweet songs to the child's soul (Parker, 1969)

\subsection{Teachers Should Integrate Stories into Their Teaching}

When Parker was made the Superintendent of the Quincy Area, he knew that children, constrained by the realities of the outside world at an early stage, will face challenges when they venture outside into the unknown and invisible world, resulting in them leading a barbaric life. The invisible world represents the sky mired by fire and fog. Dispelling myths among children is tantamount to revealing the truths of life (Parker, 1969). Therefore, stories are critical for children's learning; teachers should integrate stories into children's learning.

\subsection{Teachers Need to Motivate Children's Learning Interest}

During Parker's tenure as the Superintendent of the Quincy area when he was responsible for educational supervision and guidance, he pointed out that children's life experiences should be integrated into curriculums and recognized the critical role of interest in children's learning (Chang, 1998; Cremin, 1964). Interest was also identified as the source of life, growth, and character realization of individuals (Parker \& Helm, 1898).

Interest is an ever-present aspect of consciousness-everyone is always interested in something or the other (Parker, Cooke, \& Stilwell, 1901). Interest can be defined in two ways. First, goal attainment is always a source of fun and happiness; second, interest entails the mind's activities pertaining to goal achievement (Parker, 1897). Hence, teachers need to ignite children's learning interest (Parker \& Helm, 1898).

\subsection{Cultivating Children's Attention}

Attention captured by external object's properties can be defined as a psychological process that is both direct and partial (Parker, 1969). In other words, individuals paying attention to external objects entails a psychological process, and primary school education trains children's attention faculties. Children's attention determines the inclusion of more topics into curriculums, and the attractiveness of objects controls the will of the pupils (Parker, 1896, 1901c).

\subsection{Encouraging Children's Freedom of Expression}

During his appointment as the Superintendent of Quincy area, Parker pointed out that teachers must encourage children to express themselves in the course of learning.
Parker further pointed out that the best expressions include the clearest statement of people's thoughts, which makes it easy for listeners to comprehend the message. The best expression often requires extremely clear, logical, and concise thinking. Carelessness during expression is usually a result of carelessness in thinking. The form of expression may have considerable imperfections. Best expressions occur when the content matches the child's ability. High-quality exercises should be developed for children, and their brain development should be strengthened through self-activities. The motivation to develop depends greatly on expression in all modes (Parker, 1896, 1901a).

\subsection{Children at the Center of Education Process}

Important educational practices in Parker's life comprise educational experiments when he was the superintendent in Quincy from 1975 to 1880, teacher training and experimental schooling as the Principal of Cork County Normal School from 1883 to 1898, and his stint in the University of Chicago from 1899 to 1901, first as the Dean of the Academy and later as the Dean of the School of Education in 1901. In the process, Parker pointed out that children should be at the center of the education process (Cremin, 1964).

Parker's contribution to relevant literature has four aspects: (1) regard children as the learning subjects of education, (2) allow children to cultivate a democratic attitude in a warm community, (3) provide children with as much practical learning as possible, and (4) encourage children to express their emotions through art, literature, and sports (Huang, 2005). Cremin believed that Parker was the first person to mitigate United States' reliance on European educational theory through the creation of experimental schools built on original thoughts. Parker perceived children as the focal point of any educational process. Thus, he gave importance to guiding children's internal and active learning and advocated the development of democratic and social group attitudes. Additionally, he pointed out that children should conduct sensory learning and exploratory experiments, with nature as the setting. All these Parker's ideas have influenced the American progressive education movement (Cremin, 1964).

\section{Comments on F. W. Parker's Educational Ideas for Children}

\subsection{Parker's Claims Are Consistent with the Arguments of Western Naturalism}

Parker highlighted that nature provides people with food, clothing, and communication and transportation tools (Parker, 1901b) and is closely related to people's lives. Children take a special interest in animal and plant kingdoms (Parker, 1969). Animals, plants, and humans share an intimate relationship; plant life is linked to animal 
life and human life (Parker, 1901a).

Children imitate the call of of dogs, cats, and birds. They regard them as friends and often talk to them (Parker, 1969). Birds' nests excite children's curiosity, and they love to observe the life of these aerial beings. Animals are also considered to be friends and partners of children. For example, children on farms always show strong feelings toward horses. Flowers in forests, which embody the smile of God and signify beauty and love, always bring joy to children (Parker \& Helm, 1902).

Parker advocated that nature awakens children's energy, releases powers of imagination, and shapes and guides children's activities and unremitting energy (Parker \& Helm, 1902). Therefore, Parker believed that children should be closer to nature, especially animals and plants, because nature is closely related to humans (Parker, 1969). In the process of establishing a relationship with animals and plants and getting close to nature, children's physical and mental development can be strengthened and morals can be developed (Parker, 1896); hence, education should focus on the development of moral freedom (Merle, 1935).

Parker's narrative of nature presents the best foundation for developing morality (Parker, 1896). For example, when children are exposed to animals, they cultivate either kindness or cruelty. Generally, cruelty is a result of recklessness, indifference, and ignorance. Remedial suggestions can improve children's attitude toward animals and help them view animals as companions and friends. For example, Donald catches rabbits for fun; however, if Donald understands forest life and what would make the rabbit happier, he will release the rabbit to live freely in the forest (Parker \& Helm, 1898). This is a type of naturalistic education. Evidently, Parker was inspired by the naturalist philosophers of Rousseau, Pestalozzi, and Herbart. The naturalist educational philosophy is against the falsification and fabrication of French life. It recognizes the natural development stages of children, acknowledges individual differences, and emphasizes sensory perceptions, physical health, and moral growth of children at a deep level (Hsu, 1986).

Additionally, Parker pointed out that each child is unique; hence, when recognizing the difference between children, every new student should be perceived as a new study subject (Parker, 1897). Parker also pointed out that if children's emotional states are guided carefully, selfishness may turn into kindness, cruelty into love, deception into honesty, unpleasant moods into happy moods, conceit into humility, and stubbornness into obedience (Parker, 1896). Transformation of this nature signifies holistic moral growth. The above ideas are consistent with the arguments of Western naturalism.

\subsection{Influence of the American Progressive Education Movement}

Progressive education is termed New Education in Europe (Yang, 1982). The "new" not only signifies progress but also addresses school education's shortcomings in the context of time and space. To understand the concept of New Education, one can compare it with traditional education (Lin, 2010). There are some experimental schools that focus on fostering progressive education in the United States-an initiative that first began with Parker's experiment (Yang, 1982).

Those who visited Quincy and Cork Normal Schools were very interested in and impressed by Parker's reformation-oriented experiments. For example, Hall, the founder of the American Children's Research Movement, visited Cork Normal School every year, stating that "The visit to the Cork County Teachers' School is setting the clock for my education," a statement that indicates the inspiration Hall drew from Parker's experimental schooling (Cremin, 1964).

Parker, the pioneer of progressive education in the United States, placed great importance on the cultivation of children's social and democratic attitudes. He also emphasized that learning must stem from inherent interest and motivation and opposed the use of external means, such as competition, rewards, and punishment. American progressive educators generally followed Parker's path.

The following seven educational principles were forwarded after the establishment of the Progressive Education Association in 1919: (1) the principle of natural development, (2) motivation and interest are conducive to learning, (3) the teacher is a non-dominant guide, (4) child development necessitates scientific research; (5) all factors affecting the physical development of school children warrant attention; (6) close collaboration between schools and families helps to meet children's needs; (7) progressive schools are Leaders of educational reform (Ye, 2010).

Some of the above mentioned educational principles aligned with Parker's educational ideas for children, such as the principles of natural development, the belief that motivation and interest can promote learning, viewing teachers as guides rather than dominators, and paying attention to all factors that affect the physical development of school children. However, Parker emphasized the development of children's sociality, and this view disregards and criticizes this wave of educational reform (Wang, 2006).

Bestor emphasized that surplus attention has been paid to the problems of children and adolescents; however, the primary goal of school education is to promote students' intellectual development, which has been set aside and ignored. In the early twentieth century, the philosophy of essentialism triggered a wave of reactionary forces in the U.S. elementary and secondary schools in response to progressive curriculum reforms. In the 1930s, along with Bagley, many teachers firmly advocated that schools should focus on imparting subject knowledge and inculcating basic study skills (Wang, 2006).

Bestor, the author of the book "Restoration of Learning," argued that schools are responsible for sharpening 
children's mental abilities, and such training goals can only be achieved through scant curriculums comprising basic subject knowledge: composition, mathematics, science, history, and modern languages. Bestor also advocated that students below the university level only need to follow a single-subject study approach, and that it is inappropriate to adopt a unified learning method that integrates various disciplines until the student has entered university. This is owing to Bestor's belief that students must first acquire the knowledge of a single subject, and this different view on curriculum integration from the Essentialism (Wang, 2006).

\section{Implications of Parker's Educational Ideas for Children on Contemporary Education in Taiwan}

\subsection{Implications of Experimental Education}

Toward the end of 2014 in Taiwan, the Legislative Yuan passed the so-called three acts of experimental education, which overcame the obstacles hindering Taiwanese people from conducting multiple educational practices and free innovation. This is the result of Taiwan's democratization process. After the three acts of experimental education were promulgated, experimental education started gaining popularity in Taiwan.

The core value of experimental education lies in loosening educational regulations for experimental schools or institutions and emphasizing the autonomy of children, in turn providing children with alternative education and appropriate development. There are nine types of practices in experimental education: (1) transforming Western alternative education concepts (such as Waldorf Education and Montessori Education), (2) adopting a distinct teaching mode (such as independent learning, project teaching, and mixed-age education), (3) developing traditional, indigenous, or national cultures (such as Eastern philosophy, classical education, indigenous local culture, and national culture), (4) developing the spirit of democracy and human-oriented education (through interventions such as democratic schools, holistic education, and human-oriented education), (5) fostering a closer relationship between humans and nature (through interventions such as ecological education, natural farming laws, organic farming, and food education), (6) focusing on internal development and multiple potentials (through subjects such as education philosophy, foreign languages, mathematics, science, art, exploration, experience, and sports) (Dan, 2018; Feng, 2015; Huang, 2018; Zhang, 2017). Take Daohe Experimental Education as an example, the tangible and intangible educational environment constructed by Daohe Experimental Education combine the time sequence of nature, and combine eastern and western cultural thinking to open a window for learners to connect to world civilization, and guide learners to live and work through solar terms. Moreover, through the knowledge of sensory experience and internalization, cultivating children with the abilities of awareness, experience, reflection, integration and practice. Furthermore, cultivating children to realize the universal values and attitudes of love, peace, justice, non-violence, sustainable ecology, etc (Daohe Experimental Education, 2020).

Parker's education ideas for children advocate the spirit of humanistic education, which is consistent with the spirit of humanistic education imbibed into Taiwan's experimental education. These theories are based on humans and emphasize that teaching should focus on children's interests. Teachers are encouraged to inspire children's learning interest during lessons. In addition to providing physical guidance, teaching methods should include diverse activities. For example, outdoor teaching, acting, and conducting lessons on practical operations and handwork make for effective teaching activities. Furthermore, children's attention and observation need to be developed in the course of learning.

In addition, Parker also tried to improve the relationship between children and nature; hence, considerable attention was paid to traveling and field trips. In fact, Parker often personally led children to observe and appreciate nature to promote children's knowledge acquisition. This educational concept is consistent with Taiwan's current concept of experimental education.

Finally, Parker also paid attention to children's intrinsic development and multi-faceted potentials by studying the 10 subjects of history, ethnography, anthropology, zoology, botany, meteorology, astronomy, geography, geology and mineralogy to promote children's development and inherent potential. This educational philosophy is consistent with the current experimental education philosophy in Taiwan (Parker, 1969).

\subsection{Implications of Adaptive Education}

Teachers should understand that the purpose of humanistic democratic education is to assist in each child's individual development, highlight the child's unique existential value, and respect each child's unique characteristics. Each child is unique, and due to their differences in cultural and socioeconomic backgrounds and growth processes, children urgently require a learning method that suits their individual characteristics and needs. However, the unified teaching system and environment of schools often fail to provide opportunities for appropriate learning. Hence, it is critical to develop adaptive education. Furthermore, adaptive education offers learners with learning customized to their individual traits and helps them tap into their potential, in turn achieving self-realization. Because learners have diverse traits, abilities, gender, interests, experiences, styles, and cultures, 
they also have different learning needs. Teachers must be mindful of these differences when teaching to ensure successful learning for each student (Huang \& Zhang, 2010). Therefore, Principles of Teaching, a pre-service teacher education course, discusses the theoretical framework and methods of implementing adaptive education, so that teachers can impart more humane adaptive education among students and respond to the individual differences of each child. Parker's ideas on the learning process and the influence of nature are compatible with educational values and culture in Taiwan.

\subsection{Practice of Educational Love}

Furthermore, the love that Pestalozzi received from his mother and the educational love that affected Parker to highlight the critical role of love. Hence, Parker recognized the importance of love in the reformation process (Parker, Cooke, \& Stilwell, 1901; Tian, 1995). However, teachers should cultivate specific conditions and abilities, and their teacher training should match the students' unique needs. Following Parker's perspective of children's education, teachers should have love for children and the ability to practice love in education. In particular, in the era of globalization, technology, and lifelong learning, teachers must adapt to the continuous changes in society and perceive love as the core of education (The Ministry of Education, 2012). Educational love needs to be regarded as the starting point of improving the relationship between teachers and students. After all, the teaching profession relies on the touch of educational love.

Therefore, in History of Education, a pre-service teacher education course, some educators who practice educational love can be introduced to pre-teachers to help them understand the practice of educational love. This will help them imitate and practice educational love in their teaching process.

\section{Conclusions}

This essay offers a very nice review for F. W. Parker's educational ideas for children. Parker's educational ideas for children can be seen to be so important to the educational field in this essay.

Parker's ideas pertaining to children's education are influenced by his life events: experiencing nature on farm in his younger years, practical experience of being enrolled in teaching positions after graduation, travels and study in European countries, serving as the Superintendent of the Quincy area during which he initiated a series of educational reforms that attracted national attention, serving as the Principal of Chicago's Cook County Normal School, which included courses in professional education and emphasized practicality (Garraty \& Carnes, 1999).

No claims pertaining to children's education can have universal validity, nor can ideals be pursued blindly, ignoring the reality of one's social environment. Hence, different children's education claims should be respected and tolerated (Peng, 2010). Similarly, Parker's claims revolving children's education should be respected and tolerated, as is the case in the United States and in every part of the world. Almost all reformers who have worked with children's education in the last 100 years have transitioned to the educational route advocated by Parker. In fact, Colonel Parker critically influenced the movement reforming children's education (Harris, 1898).

It is widely known in the United States that Parker's management of Quincy School made him the most popular educator of his time (Patridge, 1896). Parker is loved by teachers in American schools, and he has been loved by a few in our history (Jackman, 1902). Courage and strength enabled Parker to strive for the highest ideals of education and overcome difficulties in his life. Dewey once said Parker's life path inspired many and called on young people to pay attention to these inspirations (Harper, Lane, Dewey, \& Hirsch, 1902). The impact and importance of Parker's views on children's education must not be divorced from his life path (Merle, 1935). For this reason, this essay searches for ideas for children's education by analyzing F. W. Parker's life path. The essay stresses on the implications these ideas have for Taiwan's education. Parker's ideas on children's education comprise the following: (1) children need to be closer to nature, (2) play can ensure a happy life in the future for children, (3) nature music should be integrated into children's learning, (4) teachers should integrate stories into their teaching, (5) teachers need to motivate children's learning interest; (6) children's attention requires cultivation, (7) children should enjoy freedom of expression, and (8) children should be at the center of education process.

Finally, Parker's education ideas for children have implications on contemporary education in Taiwan. The author discusses enlightenment from three aspects: experimental education, adaptive education, and the practice of educational love. Through this essay, a broader understanding of Parker's educational ideas for children can be gained, and this knowledge can be utilized to expand the horizon of Taiwanese education.

\section{Acknowledgements}

This research was sponsored by the Ministry of Science and Technology, Taiwan [grant number 101-2410-H-254-001-].

\section{REFERENCES}

[1] Chang, B. X. (1998). Social transformation and educational change: A study of the American progressive education 
movement. Hunan: Hunan Education Press.

[2] Chu, C. H. (2010). The revision and implication of J. F. Herbart's general pedagogy under globalization. Kaohsiung Normal University Journal: Education and Social Sciences, 29, 101-118.

[3] Cremin, L. A. (1964). The transformation of the school: Progressivism in American education (1876-1957). New York, NY: Vintage Books.

[4] Dan, J. W. (2018). Experimental education method and educational experiment. Taiwan Education Review Monthly, $7(1), 8-10$.

[5] Dangler, E. (1939). The educational philosophy of Francis Parker: Its origins, contents, and consequences (Unpublished doctoral dissertation). New York University, U.S.A.

[6] Daohe Experimental Education (2020). Educational target. Retrieved May 16, 2020, from http://www.natural-way.com .tw/target/

[7] Dewey, J. (1930). How much freedom in new school. The New Republic, 63, 204-206.

[8] Feng, C. L. (2015). Deepen roots and make dreams great-Vision for development of experimental education in Taiwan. Education in New Taipei City, 14, 13-18.

[9] Garraty, J. A., \& Carnes, M. C. (1999). American National Biography(Vol. 17). Oxford, UK: Oxford University Press.

[10] Harper, W. R., Lane, A. G., Dewey, J., \& Hirsch, E. G. (1902). In memoriam Colonel Francis Wayland Parker, late director of the school of education. The Elementary School Teacher Course of Study, 2(10), 699-715.

[11] Harris, W. T. (1898). Preface by the editor of home-reading books. In F. W. Parker \& N. L. Helm (Eds.), On the farm (pp.v-viii). New York: D. Appleton and Company.

[12] Hsu, Z. L. (1975). Parker, a pioneer of progressive education. Education Today, 28, 12-13.

[13] Hsu, Z. L. (1986). Research on western naturalistic educational thoughts. Journal of National Taiwan Normal University, 31, 1-36.

[14] Huang, K. H. (2005). Curriculum research-Review and prospect. In the Education Foundation of Professor Jia Fu-Ming (Ed), Educational masters talk about education (pp. 165-206). Taipei City: Psychological Press.

[15] Huang, J.J., \& Zhang, J. Y. (2010). Making students learn successfully: Ideas and strategies for adaptive curriculum and teaching. Curriculum and Instruction Quarterly, 13(3), $1-22$.

[16] Huang, J. J. (2018). The three methods of experimental education should be carefully considered. Taiwan Education Review Monthly, 7(1), 11-17.

[17] Jackman, W. S. (1902). Francis Wayland Parker: A retrospect. The Elementary School Teacher and Course of Study, 2(10), 734-751.

[18] Lin, H. C. (2010). What is “progressive education”. In Chou, Y. W. (Ed), Progressivism and Education (pp. 13-32). Taipei City: Shtabook.
[19] Merle, C. (1935). The social ideas of American educators. Paterson, NJ: Pageant Books, INC.

[20] Parker, F. W. (1896). Notes of talks on teaching. New York, NY: E. L. Kellogg \& co.

[21] Parker, F. W. (1897). Course of study in pedagogics. Chicago, IL: Chicago Normal School Press.

[22] Parker, F. W. (1900). The plan and purpose of the Chicago Institute. The Course of Study, 1(1), 9-16.

[23] Parker, F. W. (1901a). Function of expression in education. The Course of Study, 1(5), 398-400.

[24] Parker, F. W. (1901b). Principles of Correlation. The Course of Study, 1(6), 506-509.

[25] Parker, F. W. (1901c). Syllabus on the course of study. The Elementary School Teacher and Course of Study, 2(4), 261-263.

[26] Parker, F. W. (1902). An account of the work of the Cook County and Chicago Normal School from 1883 to 1899. The Elementary School Teacher and Course of Study, 2(10), 752-780.

[27] Parker, F. W. (1969). Talks on pedagogics. New York, NY: Arno Press.

[28] Parker, F. W., \& Helm, N. L. (1898). On the farm. New York, NY: D. Appleton \& Co.

[29] Parker, F. W., Cooke, F. J., \& Stilwell, K. M. (1901). Lectures and lessons upon the philosophy of education. The Elementary School Teacher and Course of Study, 2(1), 1-27.

[30] Parker, F. W., \& Helm, N. L. (1902). Playtime and seedtime. New York, NY: D. Appleton \& Co.

[31] Peng, H. S. (2010). British progressive education. In Chou, Y. W. (Ed), Progressivism and education (pp. 161-184). Taipei City: Shtabook.

[32] Patridge, L. E. (1896). Introduction. In F. W. Parker (Eds.), Talks on teaching (pp.5-11). New York, NY: E. L. Kellogg \& Co.

[33] Tian, P. L. (1995). Education and culture. Taipei City: Wunan.

[34] The Ministry of Education (2012). White paper on teacher education. Taipei City: The Ministry of Education

[35] Wang, H. C. (2006). Critical reflection on educational theory based on educational practice: Taking Rickover as an Example. Research Information, 23(5), 99-106.

[36] Wu, Z. H. (1995). Parker. In H. L. Chao (ed), Biography of foreign educators III (pp. 29-50). Taipei City: Laurel Book Company.

[37] Yang, K. S. (1982). Progressivism and education. Century of National Education, 18(4), 3-5.

[38] Ye, K. L. (2010). American progressive education movement. In Chou, Y. W. (Ed), Progressivism and Education (pp. 33-83). Taipei City: Shtabook.

[39] Zhang, S. F. (2017). Experimental education practice and alternative thinking of managing a school. Taiwan Education, 704, 19-21. 